\title{
High-dose IL-2 in metastatic melanoma: better survival in patients who also received patient- specific autologous tumor cell vaccine
}

\author{
Robert O Dillman ${ }^{1,2,3^{*}}$, Carol DePriest ${ }^{3}$, Stephanie E McClure ${ }^{1,2}$ \\ From Society for Immunotherapy of Cancer 28th Annual Meeting \\ National Harbor, MD, USA. 8-10 November 2013
}

Treatment with high-dose Interleukin-2 (IL-2) has been associated with long-term survival in small proportion of metastatic melanoma patients. We recently reported a median survival of 15.6 months, and a $20 \% 5$-year survival rate for 150 such patients who were hospitalized for high-dose i.v. IL-2 between May 1987 and April 2010. [1] A recent report showed a survival advantage for the addition of gp100 vaccine plus high-dose IL-2 compared to treatment with IL-2 alone [2]. We were aware that several of our IL-2 patients had also received patient-specific tumor cell vaccines derived from autologous tumor cell lines. We wished to determine whether this may have contributed to their high 5 -year survival rate. Comparison of existing data bases revealed that 27 of the $150 \mathrm{IL}-2$ patients had also received a patient-specific vaccine; 123 had not. The table below (Table 1) summarizes survival data, which was calculated from the date IL-2 was initiated. Survival was much better in patients who received a patient-specific vaccine in addition to IL-2 $(\mathrm{p}<0.001)$. That group was also younger, but age was not a predictor of survival in as much as median and 5-year survival rates were not dissimilar: 14.1 months and $23 \%$ for patients age $<50$ years at the time of IL-2, compared to 15.9 months and $17 \%$ for patients $>$ age of 50 (NSD). Of the 27 vaccine patients, 7 started vaccine therapy an average of 8.7 mos. before receiving IL-2 (range 2.4 to 40 mos.) and 20 received vaccine a median of 14.2 months after starting IL-2 (range 1 to 42 mos.); 12 received injections of irradiated autologous tumor cells and 15 received injections of dendritic cells loaded with antigens from irradiated autologous tumor cells, and suspended in 500
Table 1

\begin{tabular}{ccc}
\hline Therapy & $\mathrm{IL}-2$ & $\mathrm{IL}-2+$ Vaccine \\
\hline Portion female & $58 \%$ & $59 \%$ \\
Median age at diagnosis & $50 \mathrm{yrs}$ & $40 \mathrm{yrs}$ \\
Median age at IL-2 & $54 \mathrm{yrs}$ & $44 \mathrm{yrs}$ \\
Median age at vaccine & $\mathrm{N} / \mathrm{A}$ & 47 \\
Median survival from IL-2 & $12.8 \mathrm{mos}$ & $40.3 \mathrm{mos}$ \\
5-year survival from IL-2 & $14 \%$ & $44 \%$ \\
\hline
\end{tabular}

microgram GM-CSF. Survival was longer in patients who received IL-2 first (5-yr survival $55 \%$ vs $14 \%$ ), and in patients who received the dendritic cell vaccine (5-yr survival $53 \%$ vs $33 \%$ ). This analysis suggests that receipt of high-dose IL-2 followed by a patient specific vaccine results in better survival than IL-2 alone, but the limitations of such a retrospective analysis, and the risk of confounding unintended bias, are significant.

\section{Authors' details}

${ }^{1}$ Hoag Institute for Research and Education, Hoag Hospital, Newport Beach, CA, USA. ${ }^{2}$ Hoag Family Cancer Institute, Hoag Hospital, Newport Beach, CA, USA. ${ }^{3}$ Cancer Biotherapy Research Group, Newport Beach, CA, USA.

Published: 7 November 2013

\section{References}

1. Dillman, et al: Cancer Radiopharm Biother 2011.

2. Schwartzentruber, et al: N Engl J Med 2010.

\section{doi:10.1186/2051-1426-1-S1-P208}

Cite this article as: Dillman et al: High-dose IL-2 in metastatic melanoma: better survival in patients who also received patient-specific autologous tumor cell vaccine. Journal for ImmunoTherapy of Cancer 2013 1(Suppl 1):P208. 